\title{
Meta-analysis Exploring the Effectiveness of S-1-Based Chemotherapy for Advanced Non-Small Cell Lung Cancer
}

\author{
Xin Sun, ${ }^{1}$ Li Sun, ${ }^{1}$ Shu-Ling Zhang, ${ }^{1}$ Zhi-Cheng Xiong, ${ }^{1}$ Jie-Tao Ma ${ }^{1}$ and \\ Cheng-Bo Han ${ }^{1}$
}

${ }^{1}$ Department of Oncology, Shengjing Hospital of China Medical University, Shenyang, Liaoning, China

S-1 is a new oral fluoropyrimidine formulation that comprises tegafur, 5-chloro-2,4-dihydroxypyridine, and potassium oxonate. S-1 is designed to enhance antitumor activity and to reduce gastrointestinal toxicity. Several studies have demonstrated that both S-1 monotherapy and S-1 combination regimens showed encouraging efficacies and mild toxicities in the treatment of lung squamous cell carcinoma and adenocarcinoma. However, it is unclear whether S-1 can be used as standard care in advanced non-small cell lung cancer (NSCLC). The purpose of this meta-analysis was to assess the efficacy and safety of S-1-based chemotherapy, compared with standard chemotherapy, in patients with locally advanced or metastatic NSCLC. Thirteen randomized controlled trials (RCTs) involving 2,134 patients with a similar ratio of different pathological types were included. In first-line or second-line chemotherapy, compared with standard chemotherapy, S-1-based chemotherapy showed similar efficacy in terms of median overall survival (mOS), median progression free survival (mPFS), and objective response rate (ORR) (all P > 0.1), and significantly reduced the incidence of grade $\geq 3$ hematological toxicities. In patients with locally advanced NSCLC receiving concurrent chemoradiotherapy, compared with standard chemoradiotherapy, significantly improved survival in the S-1-based chemotherapy was noted in terms of mOS and mPFS (risk radio $[R R]=1.289, P=0.009 ; R R=1.289, P=0.000$, respectively) with lower incidence of grade $\geq 3$ neutropenia $(R R=0.453, P=0.000)$. The present meta-analysis demonstrates that $S-1$-based chemotherapy shows similar benefits in advanced NSCLC and improves survival in locally advanced NSCLC, compared with standard treatment.

Keywords: chemotherapy; chemoradiotherapy; meta-analysis; non-small cell lung cancer; S-1

Tohoku J. Exp. Med., 2017 January, 241 (1), 1-11. (C) 2017 Tohoku University Medical Press

\section{Introduction}

Lung cancer is currently a leading cause of cancerrelated death worldwide (Siegel et al. 2014). Non-small cell lung cancer (NSCLC) accounts for approximately $80 \%$ $85 \%$ of all lung cancers, $70 \%$ of which are unresectable due to locally advanced or metastatic disease at first diagnosis. Platinum-based doublet chemotherapy is still the standard care for these patients regardless of the status of epidermal growth factor receptor (EGFR) or anaplastic lymphoma kinase (ALK). Nevertheless, platinum-based doublet chemotherapy has reached an efficacy platform. Moreover, some patients are unable to tolerate the adverse events caused by platinum-based doublet chemotherapy. Thus, more effort is necessary to identify other treatments for these patients.

$\mathrm{S}-1$ is a new oral antitumor agent that contains tegafur, 5-chloro-2,4-dihydroxypyridine (CDHP), and potassium oxonate in a molar ratio of $1: 0.4: 1$ (Shirasaka et al.
1996). Tegafur is a prodrug that is metabolized to 5-fluorouracil (5-FU) in blood largely by the cytochrome P450 system in the liver, and CDHP can prolong the concentration of 5-FU in the blood and enhance the antitumor activity of 5 -FU by inhibiting dihydropyrimidine dehydrogenase, which can degrade 5-FU (Takechi et al. 1997). Potassium oxonate can decrease gastrointestinal toxicity by selectively inhibiting orotate phosphoribosyltransferase (OPRT), an enzyme which phosphorylates 5-FU to fluoropyrimidine monophosphate (FdUMP), which has been confirmed to be the main substance associated with gastrointestinal toxicity (Shirasaka et al. 1993). Due to the actions of CDHP and potassium oxonate, S-1 can increase the concentration of 5-FU and decrease the level of FdUMP, thus enhancing antitumor activity and reducing gastrointestinal toxicity (Okamoto and Fukuoka 2009).

Due to the advantages of S-1, it has been used to treat different types of cancer, such as breast cancer, head and neck cancer, and gastric cancer (Shirasaka 2009). However,

Received August 12, 2016; revised and accepted November 28, 2016. Published online December 16, 2016; doi: 10.1620/tjem.241.1. Correspondence: Cheng-Bo HAN M.D., Ph.D., Department of Oncology, Shengjing Hospital of China Medical University, Shenyang 110022, China. e-mail: hanchengbo@sj-hospital.org 
it is unclear whether it can be used in the treatment of NSCLC. A meta-analysis performed by Hamada et al. assessed the difference in efficacy between chemotherapy with Tegafur-Uracil (UFT) and the standard postoperative adjuvant chemotherapy regimen for completely resected NSCLC. This meta-analysis showed that postoperative adjuvant chemotherapy with UFT significantly improved 5and 7-year survival (Hamada et al. 2005). Several recent phase II clinical trials suggested that S-1-based chemotherapy showed favorable clinical efficacy and mild toxicities, regardless of treatment with single agent S-1 or an S-1based combination regimen (Kawahara et al. 2001; Yanagihara et al. 2010). Therefore, we conducted a metaanalysis to further assess the advantages and toxicity profile of S-1-based chemotherapy versus standard chemotherapy for the treatment of patients with locally advanced or metastatic NSCLC.

\section{Materials and Methods}

\section{Search Strategy and Study Selectio}

Search strategy: We systematically searched the following electronic databases: PubMed, Embase, Ovid Medline, ISI Web of Knowledge, Google Scholar, the Cochrane Library and the China National Knowledge Infrastructure (CNKI) database. The search date was December $31^{\text {st }}, 2015$. The computer search was supplemented with manual searches of the references listed in all retrieved articles and abstracts from meetings, such as the American Society of Clinical Oncology (ASCO), European Society for Medical Oncology (ESMO) and World Conference of Lung Cancer (WCLC) databases. The keywords used in English databases were "S-1" and "lung cancer." This article does not contain any studies with human participants performed by any of the authors.

Inclusion criteria: (1) Patients: The criteria for eligible patients included histologically or cytologically confirmed unresectable stage III locally advanced NSCLC (LA-NSCLC) or metastatic NSCLC; receiving first-line or second-line treatment for advanced NSCLC patients, or chemotherapy concurrent with thoracic radiotherapy for LA-NSCLC; an Eastern Cooperative Oncology Group (ECOG) performance status of 0 to 2 .

(2) Research type: Prospective phase II or III randomized controlled trials (RCTs) designed for patients with LA-NSCLC or metastatic NSCLC.

(3) Intervention measure: Patients were randomly assigned to two groups. In advanced NSCLC patients, the experimental group received chemotherapy including $\mathrm{S}-1$; the control group received the standard platinum-based doublet chemotherapy regimen. Only one drug was different between the two groups. In LA-NSCLC patients, thoracic radiotherapy was added to both groups. Other treatments that interfered with the outcome were not allowed.

(4) Research outcome: One of the following outcomes must be reported: median overall survival (mOS), median progression free survival (mPFS), objective response rate (ORR), or toxicity profile.

Exclusion criteria: Non-RCTs, systematic reviews, case reports and repeated published studies were excluded.

\section{Quality Assessment and Data Extraction}

Quality assessment: The risk of bias was assessed in each study following the Cochrane Collaboration guidelines (http://www. cochrane.de). This mainly included the following aspects: sequence generation, allocation concealment, blinding of participants or outcome assessment, incomplete outcome data, and selective outcome reporting.

Data Extraction: Baseline characteristics of the trials included were extracted as follows: first author's name, year of publication, number of participants, treatment regimens, line of treatment, clinical stage, pathological type, etc. We also extracted the endpoints of each trial, including the ORR, mPFS, mOS, and toxicity profile. The primary endpoint of the meta-analysis was mOS, and the secondary endpoints were ORR, mPFS and toxicities, mainly grade $\geq 3$ adverse events (AEs). In the concurrent chemoradiotherapy and first-line treatment, the version of Common Terminology Criteria for Adverse Events (CTCAE) used was 3.0. In one of the second-line RCTs, the version of CTCAE used was 4.0, and version 3.0 was used in the others.

\section{Statistical Analysis}

All data were analyzed using Stata 12.0 statistical software. The ORR and AEs were reported as risk ratios (RRs), 95\% confidence intervals (CIs) and P values, and the survival outcomes (mPFS, mOS) were reported as hazard ratios (HRs), $95 \% \mathrm{CIs}$ and $\mathrm{P}$ values. A P value $<0.05$ was considered statistically significant. The inconsistency statistic $\left(\mathrm{I}^{2}\right)$ was used to evaluate heterogeneity across studies. A fixed-effect model was used, unless potential heterogeneity existed $\left(\mathrm{I}^{2}>50 \%\right)$, in which case, a random-effect model was employed. We assessed the clinical efficacy and toxicity profile of first-line and second-line treatment for advanced NSCLC, and chemotherapy concurrent with radiotherapy for LA-NSCLC, respectively.

\section{Results}

Literature review and characteristics of the studies included

The searches identified 538 articles. We then limited the studies to randomized controlled trials and 36 studies were considered potentially eligible for further assessment. After reading the title and abstract of each article, 15 studies were excluded. According to the inclusion and exclusion criteria, 13 RCTs involving 2,134 patients were included in this study (Fig. 1). Of these trials, eight were first-line chemotherapy RCTs (Okamoto et al. 2010, Liang et al. 2012, Liu and Chen 2013, Yan and Li 2013, Chen et al. 2015, He et al. 2015, Kubota et al. 2015, Sun et al. 2015), two were second-line chemotherapy RCTs (Segawa et al. 2010a, Nishino et al. 2015), and three were concurrent chemoradiotherapy RCTs (Sugawara et al. 2013, Seto et al. 2015, Yao et al. 2015). In the first-line chemotherapy RCTs, S-1-based chemotherapy was compared with standard chemotherapy, such as gemcitabine/cisplatin (GP), docetaxel/cisplatin (TP) and paclitaxel/platinum. In the second-line chemotherapy RCTs, S-1-based chemotherapy was compared with docetaxel. In the concurrent chemoradiotherapy RCTs, S-1-based chemotherapy was compared with vinorelbine and cisplatin. The characteristics of these trials are shown in Table 1. The baseline characteristics were generally well balanced between the treatment groups in each RCT. 


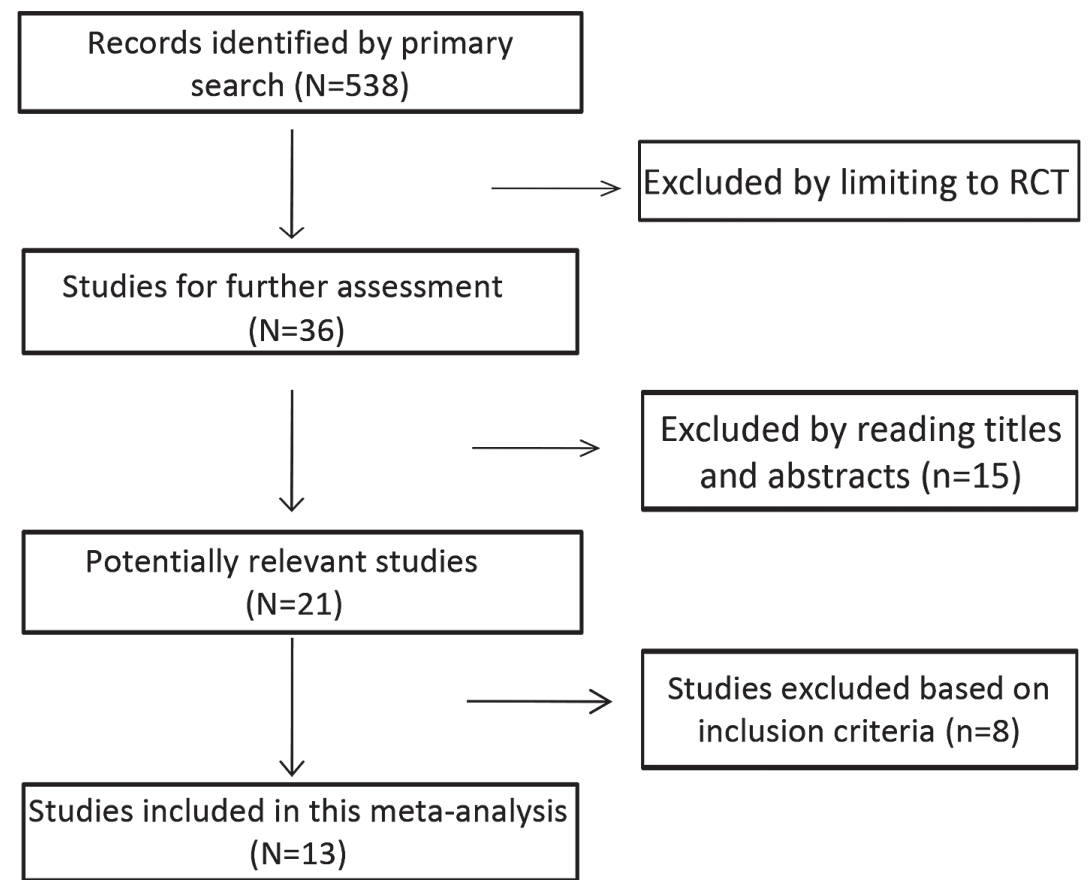

Fig. 1. Trial selection flow chart.

Table 1. The characteristics of the studies included.

\begin{tabular}{|c|c|c|c|c|}
\hline Study & Treatment arms & Cases & Endpoints & Histologies \\
\hline Chen et al. 2015 & $\begin{array}{c}\text { S-1 and cisplatin } \\
\text { paclitaxel and cispaltin }\end{array}$ & $\begin{array}{l}40 \\
40\end{array}$ & ORR/DCR & unmentioned \\
\hline He et al. 2015 & $\begin{array}{c}\text { S-1 and cisplatin } \\
\text { docetaxel and cisplatin }\end{array}$ & $\begin{array}{l}124 \\
122\end{array}$ & $\mathrm{mPFS} / \mathrm{mOS}$ & unmentioned \\
\hline Kubota et al. 2015 & $\begin{array}{c}\text { S-1 and cisplatin } \\
\text { docetaxel and cisplatin }\end{array}$ & $\begin{array}{l}301 \\
295\end{array}$ & OS/PFS/TTF/ORR/QOL & Ade.,SCC.,ASC.,LCC.,other \\
\hline Liang et al. 2012 & $\begin{array}{l}\text { S-1 and cisplatin } \\
\text { gemcitabin and cisplatin }\end{array}$ & $\begin{array}{l}44 \\
51\end{array}$ & $\mathrm{ORR} / \mathrm{DCR} / \mathrm{mPFS}$ & Ade.,non-Ade. \\
\hline Liu and Chen 2013 & $\begin{array}{c}\text { S-1 and cisplatin } \\
\text { docetaxel and cisplatin }\end{array}$ & $\begin{array}{l}22 \\
22\end{array}$ & $\mathrm{ORR} / \mathrm{mPFS} / \mathrm{mOS}$ & Ade.,SCC. \\
\hline Okamoto et al. 2010 & $\begin{array}{c}\text { S-1 and carboplatin } \\
\text { paclitaxel and carboplatin }\end{array}$ & $\begin{array}{l}279 \\
279\end{array}$ & OS/ORR/QOL/PFS & Ade.,non-Ade. \\
\hline Sun et al. 2015 & $\begin{array}{c}\text { S-1 and cisplatin } \\
\text { gemcitabin and cisplatin }\end{array}$ & $\begin{array}{l}34 \\
34\end{array}$ & $\mathrm{ORR} / \mathrm{mPFS}$ & Ade.,SCC. \\
\hline Yan and Li 2013 & $\begin{array}{l}\text { S-1 and docetaxel } \\
\text { cisplatin and docetaxel }\end{array}$ & $\begin{array}{l}43 \\
40\end{array}$ & ORR & Ade.,SCC.,other \\
\hline Nishino et al. 2015 & $\begin{array}{c}\text { S-1+bevacizumab } \\
\text { docetaxel+bevacizumab }\end{array}$ & $\begin{array}{l}45 \\
45\end{array}$ & $\mathrm{PFS} / \mathrm{OS}$ & Ade.,Unclassified NSCLC \\
\hline Segawa et al. 2010a & $\begin{array}{l}\text { S-1 and docetaxel } \\
\text { docetaxel }\end{array}$ & $\begin{array}{l}31 \\
29\end{array}$ & $\mathrm{ORR} / \mathrm{mPFS} / \mathrm{mOS}$ & Ade.,SCC.,other \\
\hline Sugawara et al. 2013 & $\begin{array}{l}\text { UP+TRT } \\
\mathrm{NP}+\mathrm{TRT}\end{array}$ & $\begin{array}{l}35 \\
31\end{array}$ & ORR/PFS/OS & Ade.,SCC.,LCC.,other \\
\hline Seto et al. 2015 & $\begin{array}{c}\text { S-1/cisplatin / TRT } \\
\text { vinorelbine/cisplatin/TRT }\end{array}$ & $\begin{array}{l}54 \\
54\end{array}$ & $\mathrm{PFS} / 2 \mathrm{yr}-\mathrm{OS}$ & unmentioned \\
\hline Yao et al. 2015 & $\begin{array}{l}\text { S-1/cisplatin / TRT } \\
\text { cisplatin / TRT }\end{array}$ & $\begin{array}{l}20 \\
20\end{array}$ & OS/PFS/ORR & Ade.,SCC.,other \\
\hline
\end{tabular}

The cases and histologies of each RCT were generally well balanced between the treatment groups in each RCT.

Ade., adenocarcinoma; SCC., squamous cell carcinoma; LCC., large cell carcinoma; ASC., adenosquamous carcinoma; mOS, median overall survival; mPFS, median progression free survival; TTF, time to failure; DCR, disease control rate; ORR, objective response rate; QOL, quality of life; TRT, thoracic radiotherapy. 
Quality assessment, heterogeneity analysis, and publication bias

All trials were assessed using the Cochrane Collaboration tool, except the two conference abstracts, as we were unable to obtain the full text. This tool includes the following aspects: sequence generation, allocation concealment, blinding of participants or outcome assessment, incomplete outcome data, and selective outcome reporting. The results are shown in Table 2. The assessment results demonstrated that of the eleven RCTs, seven RCTs were of high quality scoring 4 to 7 , and four RCTs were of low quality scoring 1 to 3 .
Meta-analysis of the efficacy and toxicity profile of S-1based chemotherapy versus standard chemotherapy in different lines of treatment

HR was used to assess the mOS, and mPFS in firstand second-line treatment. RR was used to assess the ORR and due to lack of HR, the mOS and mPFS in concurrent chemotherapy were also measured by RR. Each of the studies included reported AEs and the most common toxicities were leukopenia, neutropenia, febrile neutropenia and diarrhea. RR was used to assess the safety profile. The toxicities are shown in Table 3.

Table 2. Quality assessment by the Cochrane Collaboration's tool.

\begin{tabular}{|c|c|c|c|c|c|}
\hline Study & Randomization & Allocation concealment & Blindness & ITT analysis & score \\
\hline Chen et al. 2015 & mentioned & not mentioned & not mentioned & Yes & 2 \\
\hline Kubota et al. 2015 & mentioned & centralized & not mentioned & Yes & 4 \\
\hline Liang et al. 2012 & not mentioned & not mentioned & not mentioned & Yes & 1 \\
\hline Liu and Chen 2013 & mentioned & not mentioned & not mentioned & Yes & 2 \\
\hline Nishino et al. 2015 & mentioned & centralized & not mentioned & Yes & 4 \\
\hline Okamoto et al. 2010 & mentioned & centralized & not mentioned & Yes & 4 \\
\hline Segawa et al. $2010 \mathrm{a}$ & mentioned & mentioned & not mentioned & Yes & 4 \\
\hline Sugawara et al. 2013 & mentioned & not mentioned & not mentioned & Yes & 2 \\
\hline Sun et al. 2015 & random number table & mentioned & not mentioned & Yes & 4 \\
\hline Yan and Li 2013 & random number table & not mentioned & not mentioned & Yes & 4 \\
\hline Yao et al. 2015 & mentioned & mentioned & mentioned & Yes & 6 \\
\hline
\end{tabular}

The quality assessment results of each RCT per the Cochrane Collaboration's tool were showed except two conference abstracts [He et al. 2015, Seto et al. 2015]. Seven RCTs were of high quality scoring 4 to 7, and four RCTs were of low quality scoring 1 to 3 .

Table 3. Toxicity of S-1 based chemotherapy versus standard chemotherapy in different lines of treatment.

\begin{tabular}{lccccc}
\hline Toxicities & N & RR (95\%CI) & P & \multicolumn{2}{c}{ Heterogeneity } \\
\cline { 5 - 6 } $\mathbf{I}^{\mathbf{2}} \mathbf{( \% )}$ & $\mathbf{P}$ \\
\hline First-line treatment & & & & & \\
$\quad$ Leukopenia & 6 & $0.260(0.124-0.545)$ & 0.000 & 90.5 & 0.000 \\
Neutropenia & 4 & $0.243(0.159-0.370)$ & 0.000 & 73.8 & 0.009 \\
Thrombocytopenia & 6 & $1.214(0.431-3.421)$ & 0.714 & 89.8 & 0.000 \\
Febrile neutropenia & 3 & $0.142(0.065-0.310)$ & 0.000 & 0.0 & 0.992 \\
$\quad$ Diarrhea & 3 & $1.709(0.970-3.009)$ & 0.064 & 0.0 & 0.497 \\
Second-line treatment & & & & & \\
Leukopenia & 2 & $0.168(0.001-29.52)$ & 0.499 & 96.3 & 0.000 \\
Neutropenia & 2 & $0.233(0.008-7.167)$ & 0.405 & 97.3 & 0.000 \\
Febrile neutropenia & 2 & $0.075(0.014-0.389)$ & 0.002 & 31.0 & 0.229 \\
Concurrent chemoradiotherapy & & & & \\
Leukopenia & 2 & $0.620(0.192-2.002)$ & 0.424 & 68.2 & 0.076 \\
Neutropenia & 3 & $0.453(0.322-0.637)$ & 0.000 & 32.9 & 0.225 \\
Thrombocytopenia & 3 & $1.408(0.569-3.480)$ & 0.459 & 0.0 & 0.637 \\
Febrile neutropenia & 3 & $0.505(0.232-1.098)$ & 0.085 & 4.2 & 0.352 \\
Diarrhea & 3 & $2.512(0.590-10.695)$ & 0.213 & 8.8 & 0.334 \\
\hline
\end{tabular}

a. $\mathrm{N}$ represents the number of included trials.

b. In first-line treatment, the toxicity profile of S-1-based chemotherapy was much lower than that of the standard chemotherapy regimen in terms of the incidence of grade $\geq 3$ leukopenia, neutropenia and febrile neutropenia. In second-line treatment, the incidence of febrile neutropenia of S-1-based chemotherapy is much lower than that of standard regimen. In concurrent chemoradiotherapy, the incidence of neutropenia is much lower than that of standard regimen. 


\section{First-line chemotherapy for advanced NSCLC}

In first-line treatment for advanced NSCLC, three RCTs including 1,400 patients assessed OS and PFS, and seven RCTs including 1,524 patients assessed ORR. With regard to AEs, six RCTs including 1,626 patients reported leukopenia, four RCTs including 1,439 patients reported the incidence of neutropenia, three RCTs including 1,395 patients reported the incidence of febrile neutropenia, and three RCTs including 1,224 patients reported the incidence of diarrhea.

(1) Primary endpoint: mOS

The fixed-effect model was used due to slight heterogeneity across the studies $\left(\mathrm{I}^{2}=0.0 \%, \mathrm{P}=0.681\right)$. The pooled HR was 0.962 (95\% CI: 0.836-1.108, $\mathrm{P}=0.592$ ), which indicated that S-1-based chemotherapy showed no obvious difference in OS compared with standard chemotherapy (Fig. 2a).

(2) Secondary endpoints: mPFS, ORR, and AEs

$m P F S$ and ORR: The random-effect model was used to analyze mPFS and ORR as obvious heterogeneity across the studies was observed $\left(\mathrm{I}^{2}=68.6 \%, \mathrm{P}=0.041 ; \mathrm{I}^{2}=63.7 \%\right.$, $\mathrm{P}=0.011$, respectively). The results revealed no significant difference in mPFS and ORR in patients who received S-1based chemotherapy compared to those who received standard chemotherapy $(\mathrm{HR}=1.009,95 \% \mathrm{CI}: 0.901-1.130, \mathrm{P}=$ 0.873 and $\mathrm{RR}=0.886,95 \% \mathrm{CI}: 0.674-1.164, \mathrm{P}=0.384$, respectively) (Fig. 2b, c).

$A E s$ : The results showed that the toxicity profile of S-1-based chemotherapy was much lower than that of the standard chemotherapy regimen in terms of the incidence of grade $\geq 3$ leukopenia, neutropenia and febrile neutropenia. The pooled RR was 0.260 (95\% CI: 0.124-0.545, P = $0.000)$ for leukopenia, 0.243 (95\% CI: $0.159-0.370, \mathrm{P}=$ $0.000)$ for neutropenia, and 0.142 (95\% CI: 0.065-0.310, P $=0.000)$ for febrile neutropenia, respectively. However, there was no significant difference between S-1-based chemotherapy and the standard chemotherapy regimen in terms of the incidence of grade $\geq 3$ diarrhea. The pooled RR was 1.709 (95\% CI: 0.970-3.009, $\mathrm{P}=0.064)$.

\section{Second-line chemotherapy for advanced NSCLC}

In second-line treatment for advanced NSCLC, two RCTs including 150 patients assessed mOS, mPFS, ORR and AEs.

\section{(1) Primary endpoint: mOS}

The random-effect model was employed due to obvious heterogeneity $\left(\mathrm{I}^{2}=80.6 \%, \mathrm{P}=0.023\right)$. The results suggested that treatment with S-1-based chemotherapy showed no obvious difference in mOS compared to treatment with the standard docetaxel chemotherapy. The pooled HR was 0.752 (95\% CI: 0.259-2.183, P=0.600) (Fig. 3a).

(2) Secondary endpoints: mPFS, ORR, and AEs

$m P F S$ and $O R R$ : The fixed-effect model was employed in $\mathrm{mPFS}\left(\mathrm{I}^{2}=0.0 \%, \mathrm{P}=0.713\right)$, and the random-effect model was used in ORR $\left(\mathrm{I}^{2}=67.9 \%, \mathrm{P}=0.078\right)$. The results suggested that compared with the standard docetaxel chemotherapy, S-1-based chemotherapy resulted in similar clinical efficacy in terms of mPFS and ORR (HR $=0.797$, 95\% CI: $0.555-1.145, \mathrm{P}=0.220 ; \mathrm{RR}=0.351,95 \% \mathrm{CI}$ : 0.048-2.563, $\mathrm{P}=0.302$, respectively) (Fig. 3b, c).

$A E s$ : The results indicated that the incidence of grade $\geq 3$ febrile neutropenia with S-1-based chemotherapy was much higher than that with the standard chemotherapy (RR $=0.075,95 \% \mathrm{CI}: 0.014-0.389, \mathrm{P}=0.002)$, and other toxicities due to S-1-based chemotherapy were similar to those of the standard chemotherapy regimen in terms of grade $\geq 3$ leukopenia, and neutropenia $(\mathrm{RR}=0.168,95 \% \mathrm{CI}$ : 0.001 29.52, $\mathrm{P}=0.499 ; \mathrm{RR}=0.233,95 \% \mathrm{CI}: 0.008-7.167, \mathrm{P}=$ 0.405 , respectively).

\section{Concurrent chemoradiotherapy for LA-NSCLC}

Of the RCTs that assessed concurrent chemoradiotherapy for LA-NSCLC, two RCTs including 106 patients reported $\mathrm{mOS}$ and ORR, and three RCTs including 214 patients reported mPFS. With regard to AEs, three RCTs including 214 patients reported the incidence of neutropenia, febrile neutropenia and diarrhea, and two RCTs including 106 patients reported the incidence of leukopenia.

(1) Primary endpoint: mOS

The fixed-effect model was used $\left(\mathrm{I}^{2}=0.0 \%, \mathrm{P}=\right.$ 0.605). The pooled RR for mOS was 1.289 (95\% CI: 1.066-1.559, $\mathrm{P}=0.009)$, suggesting that compared with the standard concurrent chemoradiotherapy, treatment with S-1-based chemoradiotherapy significantly improved the mOS (Fig. 4a).

(2) Secondary endpoints: mPFS, ORR, and AEs

$m P F S$ and ORR: The fixed-effect model was used due to slight heterogeneity between the studies $\left(\mathrm{I}^{2}=0.0 \%, \mathrm{P}=\right.$ 0.390 for $\mathrm{mPFS} ; \mathrm{I}^{2}=0.0 \%, \mathrm{P}=0.840$ for ORR). The pooled RR for mPFS was 1.289 (95\% CI: 1.128-1.473, P = 0.000) in favor of S-1-based chemoradiotherapy (Fig. 4b), but the ORR of S-1-based chemoradiotherapy was not significantly different to that of the standard chemoradiotherapy $(\mathrm{RR}=1.149$, 95\% CI: 0.886-1.490, $\mathrm{P}=0.295)$ (Fig. 4c).

AEs: The results indicated that the incidence of grade $\geq 3$ neutropenia with $\mathrm{S}$-1-based chemotherapy was much lower than that with the standard chemoradiotherapy $(\mathrm{RR}=$ $0.453,95 \%$ CI: $0.322-0.637, \mathrm{P}=0.000)$, and the incidence of grade $\geq 3$ leukopenia, febrile neutropenia and diarrhea was similar to that with the standard chemoradiotherapy $(\mathrm{RR}=0.620,95 \% \mathrm{CI}: 0.192-2.002, \mathrm{P}=0.424 ; \mathrm{RR}=0.505$, 95\% CI: $0.232-1.098, \mathrm{P}=0.085 ; \mathrm{RR}=2.512,95 \% \mathrm{CI}$ : $0.590-10.695, \mathrm{P}=0.213$, respectively).

\section{Discussion}

S-1 is a novel oral anti-tumor drug, and its activity has been confirmed by a large number of clinical trials (Okamoto and Fukuoka 2009). However, the clinical efficacy of S-1 in NSCLC is still controversial. The present meta-analysis confirmed that the clinical efficacy of S-1based chemotherapy was not worse than that of standard 
(a)

Study

ID

HR $(95 \% \mathrm{Cl}) \quad$ Weight

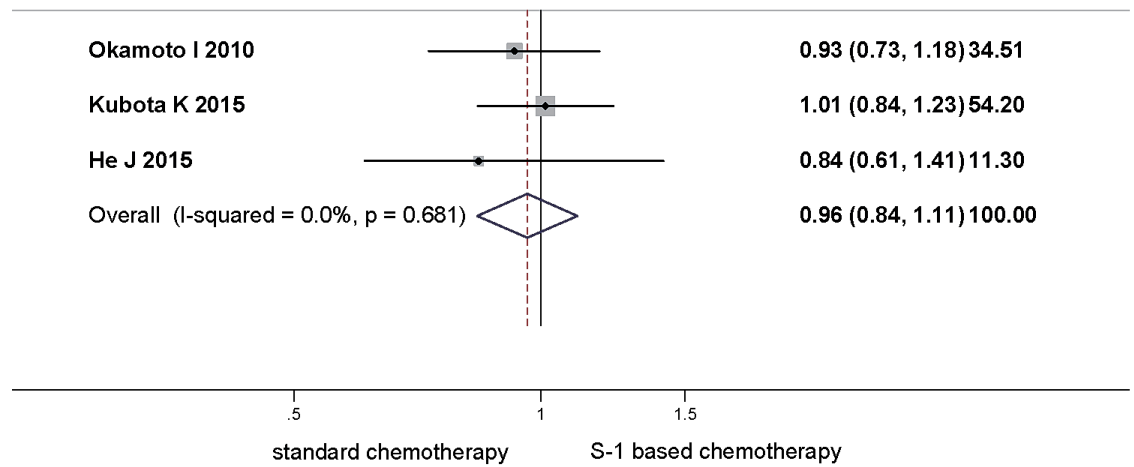

(b)

Study

ID

HR $(95 \% \mathrm{Cl}) \quad$ Weight

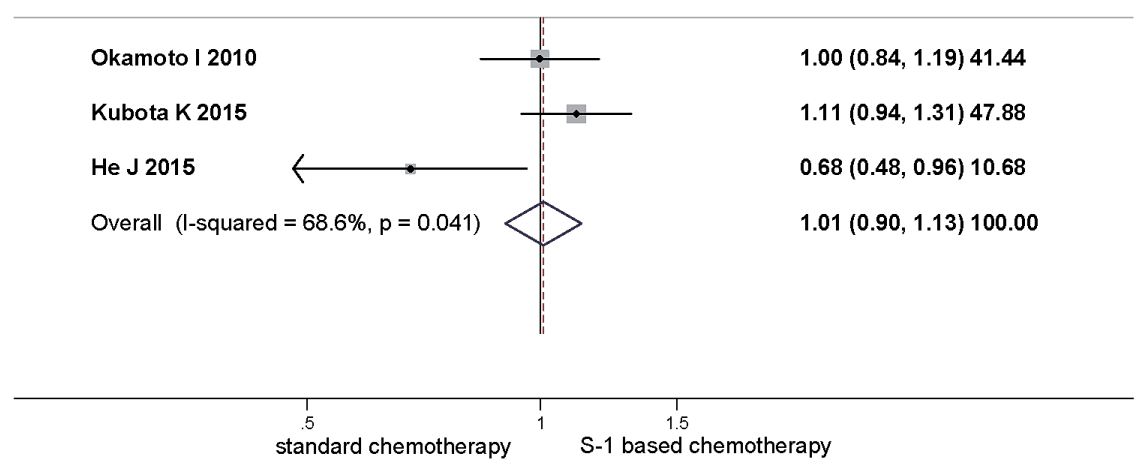

(c)

\begin{tabular}{|c|c|c|c|}
\hline \multicolumn{2}{|l|}{ Study } & \multicolumn{2}{|r|}{$\%$} \\
\hline ID & & $\operatorname{RR}(95 \% \mathrm{Cl})$ & Weight \\
\hline Yan and Li 2013 & $\longrightarrow$ & $1.42(1.05,1.92$ & 19.40 \\
\hline Liang H 2012 & & $0.89(0.43,1.83$ & 9.23 \\
\hline Liu and Chen 2013 & & $0.90(0.46,1.78$ & 9.90 \\
\hline Chen CJ 2015 & & $0.44(0.22,0.90$ & 9.40 \\
\hline Sun CH 2015 & & $1.08(0.60,1.94$ & 11.73 \\
\hline Okamoto I 2010 & & $0.70(0.52,0.95$ & 19.61 \\
\hline Kubota K 2015 & & $0.86(0.66,1.11$ & 20.73 \\
\hline Overall $(I-$ squared $=63.7 \%, p=0.011)$ & & $0.89(0.67,1.16$ & 100.00 \\
\hline NOTE: Weights are from random effects analysis & & & \\
\hline .219 & & 1.57 & \\
\hline
\end{tabular}

Fig. 2. Forest plot of first-line treatment for advanced non-small cell lung cancer.

Comparison between S-1-based chemotherapy and standard chemotherapy in terms of mOS (a), mPFS (b), and ORR (c).

chemotherapy, in terms of ORR, mPFS and mOS. Specifically, LA-NSCLC patients treated with S-1-based concurrent chemoradiotherapy had significantly improved survival compared with standard chemoradiotherapy. The incidence of grade $\geq 3$ AEs with S-1-based chemotherapy was much lower than that with the standard chemotherapy.

For the treatment of stage III unresectable LA-NSCLC, platinum-based chemotherapy with concurrent thoracic 
(a)

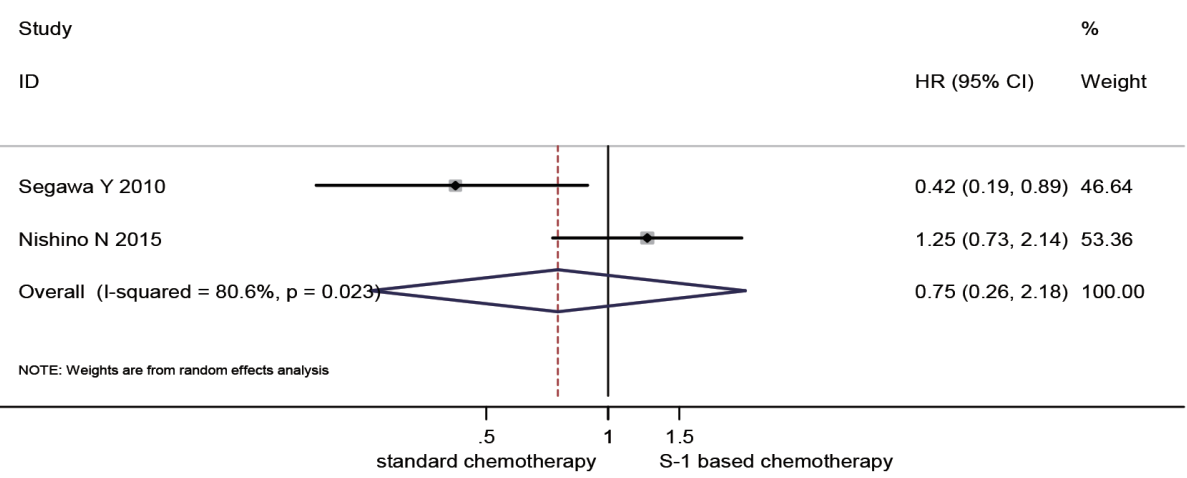

(b)

Study $\%$

ID

HR $(95 \% \mathrm{Cl}) \quad$ Weight

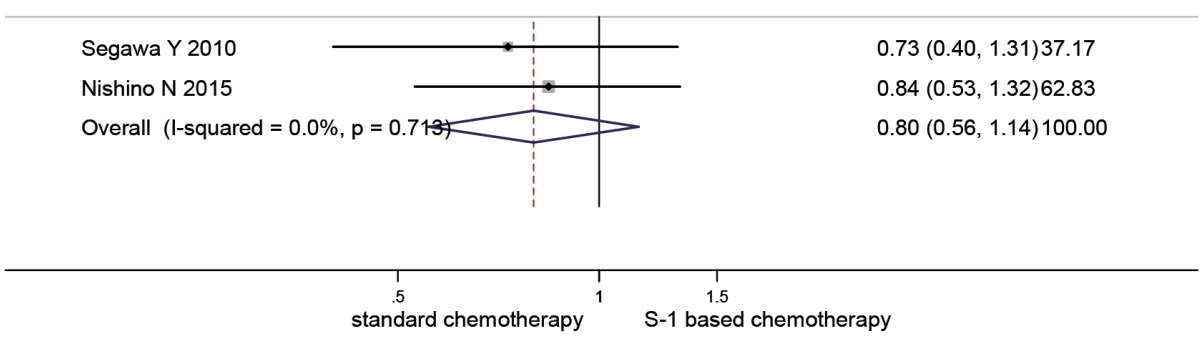

(c)
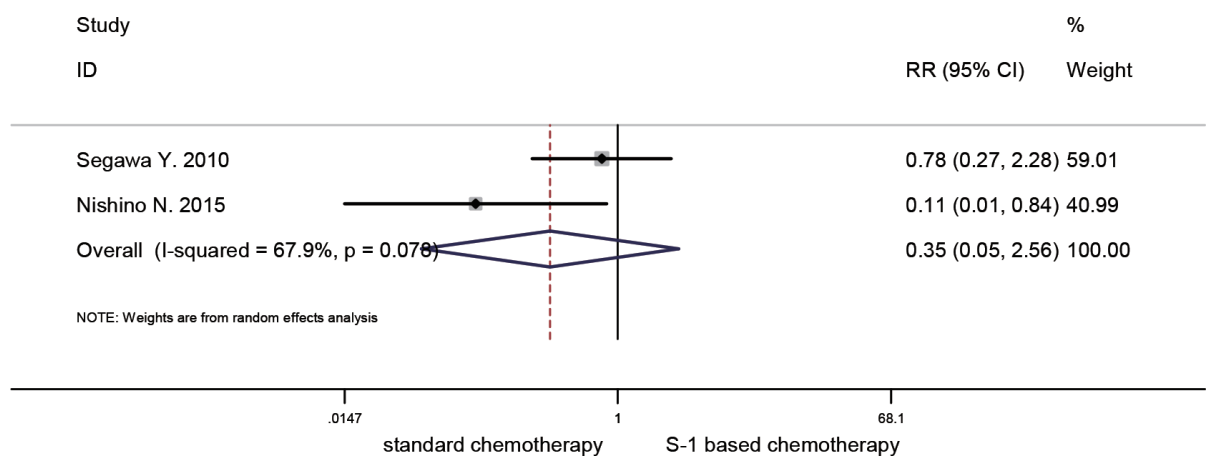

Fig. 3. Forest plot of second-line treatment for advanced non-small cell lung cancer.

Comparison between S-1-based chemotherapy and standard chemotherapy in terms of mOS (a), mPFS (b), and ORR (c).

radiation therapy is the standard regimen. The Radiation Therapy Oncology Group (RTOG) 0617 study showed that a high dose of radiotherapy ( $\geq 74 \mathrm{~Gy}$ ) combined with chemotherapy resulted in significantly poorer disease control and survival compared with standard dose radiotherapy (60 Gy) (Bradley et al. 2015). Thus, the development of combination chemotherapy will be a focus in the future. Several prospective clinical trials have demonstrated that there was no significant difference in clinical efficacy between second-generation and third-generation chemotherapeutic regimens; however, the toxicity profile of thirdgeneration regimens was relatively mild (Segawa et al. 2010b, Yamamoto et al. 2010a). Therefore, it is crucial to explore new chemotherapeutic regimens with efficient anticancer activity and fewer adverse effects. The PROCLAIM study, a phase 3 clinical trial, attempted to identify which chemotherapy regimen is best for patients with locally advanced non-squamous NSCLC. The preliminary results showed that despite the high anticancer activity of pemetrexed relative to the other drugs, there were no differences in mOS (26.8 months vs. 25 months), and 3-year survival rates $(40 \%$ vs. $37 \%)$ between the pemetrexed plus cisplatin group and the etoposide plus cisplatin group. The toxicity profile differed in the two groups, and a significantly lower incidence of drug-related grade $\geq 3$ AEs was found in the pemetrexed group compared with the etoposide group (Senan et al. 2015). An early study revealed that combination treatment with cisplatin and 5-FU may cause synergistic cytotoxicity in NSCLC cells (Tsai et al. 1993). Due to the advantages of S-1, which include high antitumor activ- 
(a)

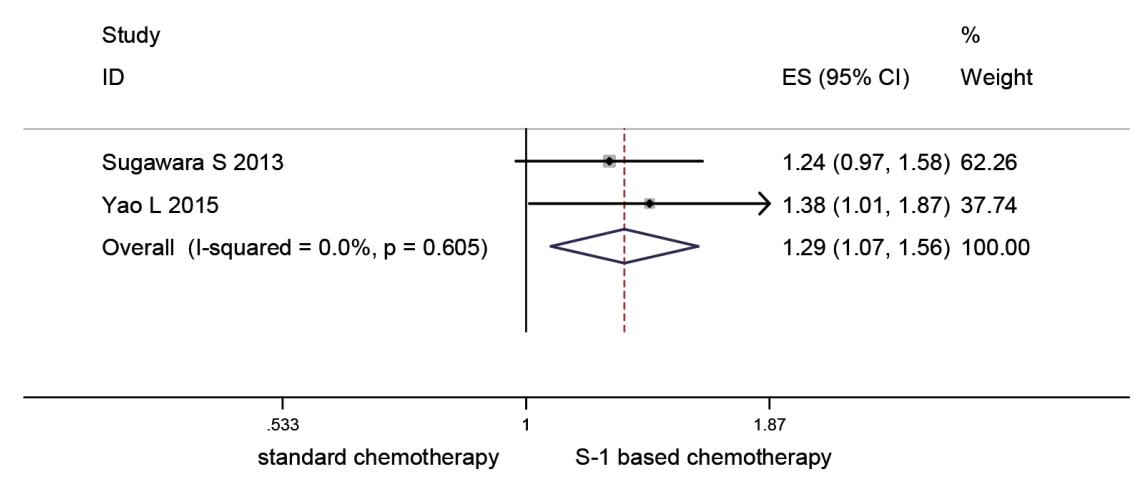

(b)

Study

ID

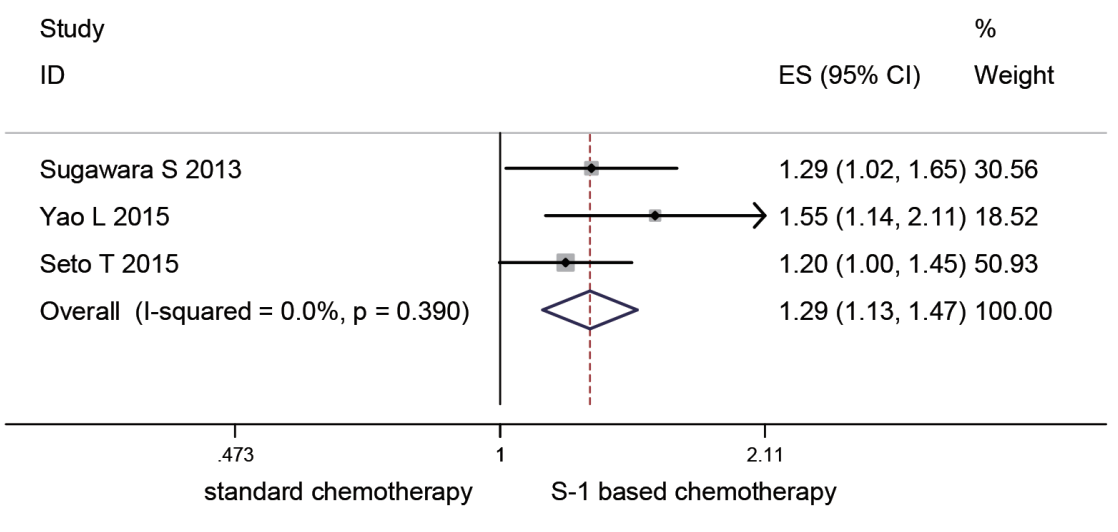

(c)

Study

ID

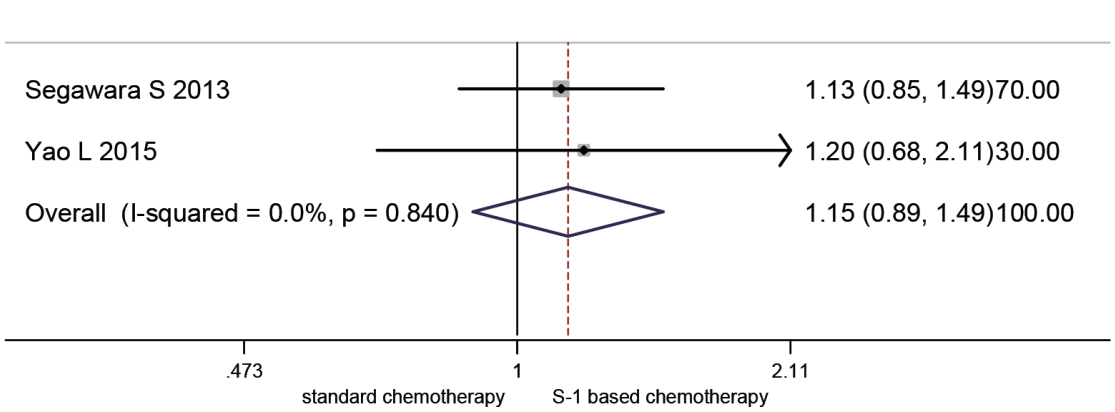

Fig. 4. Forest plot of concurrent chemoradiotherapy for locally advanced non-small cell lung cancer.

Comparison between S-1-based chemotherapy and standard chemotherapy in terms of mOS (a), mPFS (b), and ORR (c).

ity and fewer AEs, clinical trials have recently been carried out to determine the efficacy and safety of S-1 combined with concurrent thoracic radiation therapy in patients with LA-NSCLC. A retrospective trial revealed that S-1-based chemotherapy had a similar mPFS (327 days vs. 328 days) and $\operatorname{mOS}$ (1,012 days vs. 905 days) (Shukuya et al. 2012). The OLCSG trial 0501 was conducted to evaluate the clinical efficacy of combination chemotherapy consisting of S-1 and cisplatin with concurrent thoracic radiation, and the results indicated that a partial response was observed in $77 \%$ patients, and the mPFS and mOS were 9.3 months and 31.3 months, respectively (Nogami et al. 2015). The same results were also observed in several phase II or III studies of S-1. As reported in the NJLCG 0601 study, S-1-based chemotherapy resulted in better mPFS (8.8 months vs. 6.8 months) and mOS (26.9 months vs. 21.7 months) compared with the standard chemoradiotherapy group. Importantly, S-1-based chemoradiotherapy resulted in a significant decrease in the incidence of febrile neutropenia and other toxicities (Sugawara et al. 2013).

For the treatment of advanced or metastatic NSCLC without EGFR activating mutations or ALK gene rearrangements, platinum-based doublet chemotherapy is currently still the standard first-line treatment. Clinical trials have 
proved that third-generation chemotherapeutic drugs such as docetaxel, paclitaxel, vinorelbine and gemcitabine can improve survival in patients with advanced NSCLC. In addition, the ECOG 1594 trial indicated that there was no difference in efficacy between the four chemotherapy regimens (Schiller et al. 2002). Although great progress has been made in chemotherapy treatment, the mOS is no more than 12 months using platinum-based chemotherapeutic regimens (Klastersky and Awada 2012). This meta-analysis showed there was no difference with respect to mOS, mPFS, and ORR between S-1-based chemotherapy and the standard chemotherapy. It should be noted that S-1-based chemotherapy was much safer than the standard chemotherapy, regardless of first-line or second-line treatment. Specifically, first-line S-1-based chemotherapy resulted in a significant decrease in the incidence of grade $\geq 3$ hematological toxicities such as leukopenia, neutropenia and febrile neutropenia. In second-line chemotherapy, S-1based chemotherapy resulted in a significant decrease in the incidence of grade $\geq 3$ febrile neutropenia.

A recently published meta-analysis (Abdel-Rahman and ElHalawani 2016) also compared the efficacy and toxicity of standard chemotherapy and chemotherapy involving S-1. We both have reached the same conclusion that there was no significant difference in $\mathrm{mOS}, \mathrm{mPFS}$ and ORR in first- and second-line treatment of advanced NSCLC. However, in our meta-analysis, we included more studies (13 studies) and all included trials were RCTs. In contrast, only eight studies were included in the previous meta-analysis, including a retrospective study. Importantly, we found that S-1-based chemoradiotherapy significantly improved survival compared with standard chemoradiotherapy for LA-NSCLC with tolerable toxicity profiles, although the results may have been influenced by the histologic types and subsequent treatment such as target therapies for patients who were EGFR mutation or ALK translocation positive. However, among the 13 RCTs included in this meta-analysis, only one RCT reported efficacy based on histology. The updated results of the West Japan Oncology Group LETS study (Yoshioka et al. 2013) confirmed that no association was observed between histology and efficacy for mPFS and mOS, although S-1 plus carboplatin showed a possible survival advantage, compared with the carboplatin plus paclitaxel group (14.0 months vs. 10.6 months) for first-line treatment of patients with squamous cell carcinoma (SCC). However, the limitation was that EGFR mutation or ALK rearrangement were not evaluated. A pooled analysis conducted by Yamamoto et al. (2010b) also analyzed the efficacy of S-1 and cisplatin according to histological type, and the results demonstrated that PFS and ORR did not differ significantly. However, OS differed according to histological type, OS of non-squamous cell carcinoma (non-SCC) was longer than that of SCC (14.1 months vs. 7.4 months), which may have been caused by the subsequent use of EGFR tyrosine kinase inhibitors (EGFR-TKIs) (Yamamoto et al. 2010b).
There are some limitations in our meta-analysis. The RCTs included were insufficient, especially those focused on the second-line treatment of advanced NSCLC and the concurrent chemoradiotherapy treatment of LA-NSCLC. In addition, some RCTs did not report all the data required, and two RCTs were conference abstracts which contained incomplete data. Also obvious heterogeneity was observed in some RCTs. Furthermore, these were early studies and the detection of EGFR mutation was still uncommon, thus most studies did not evaluate the influence of EGFR mutation status on the efficacy of S-1-based chemotherapy. Therefore, more well-designed RCTs are needed to further confirm the efficacy and safety of S-1 in NSCLC.

In conclusion, our meta-analysis confirmed that S-1based chemotherapy for the treatment of both LA-NSCLC and advanced NSCLC had favorable efficacy and a tolerable toxicity profile. Overall survival in patients treated with S-1-based chemotherapy was similar to that following treatment with standard first-line or second-line chemotherapy, and superior to that following treatment with standard chemotherapy when combined with concurrent thoracic radiotherapy for LA-NSCLC. The toxicity profile of S-1-based chemotherapy was much milder than that of the latter. We believe that S-1-based chemotherapy may become a standard regimen for LA-NSCLC and advanced NSCLC, and is especially suitable for patients who are unable to tolerate the toxicity of standard chemotherapy.

\section{Conflict of Interest}

The authors declare no conflict of interest.

\section{References}

Abdel-Rahman, O. \& ElHalawani, H. (2016) S-1-based regimens for locally advanced/metastatic non-small-cell lung cancer: a meta-analysis. Future Oncol., 12, 701-713.

Bradley, J.D., Paulus, R., Komaki, R., Masters, G., Blumenschein, G., Schild, S., Bogart, J., Hu, C., Forster, K., Magliocco, A., Kavadi, V., Garces, Y.I., Narayan, S., Iyengar, P., Robinson, C., et al. (2015) Standard-dose versus high-dose conformal radiotherapy with concurrent and consolidation carboplatin plus paclitaxel with or without cetuximab for patients with stage IIIA or IIIB non-small-cell lung cancer (RTOG 0617): a randomised, two-by-two factorial phase 3 study. Lancet Oncol., 16, 187-199.

Chen, C., Chen, C., Lin, Y., Tan, B., Pan, Q. \& Xie, F. (2015) Clinical comparative analysis of gimeracil and oteracil porassium capsules and platinum on elderly advanced non-smallcell lung cancer. Journal of Gannan Medical University, 35, 73-75.

Hamada, C., Tanaka, F., Ohta, M., Fujimura, S., Kodama, K., Imaizumi, M. \& Wada, H. (2005) Meta-analysis of postoperative adjuvant chemotherapy with tegafur-uracil in non-smallcell lung cancer. J. Clin. Oncol., 23, 4999-5006.

He, J., Shi, Y., Chang, J., Wang, M., Han, B., Liu, X., Chen, G., Zhou, C., Liu, J., Pan, H., Huang, C., Zhang, S., Feng, J., Lin, X., Wang, J., et al. (2015) An open-label, randomized, multicenter, phase III study of S-1 and cisplatin versus docetaxel and cisplatin in patients with untreated advanced non-smallcell lung cancer. J. Clin. Oncol., 33, suppl; abstr 8039.

Kawahara, M., Furuse, K., Segawa, Y., Yoshimori, K., Matsui, K., Kudoh, S., Hasegawa, K. \& Niitani, H. (2001) Phase II study 
of S-1, a novel oral fluorouracil, in advanced non-small-cell lung cancer. Br. J. Cancer, 85, 939-943.

Klastersky, J. \& Awada, A. (2012) Milestones in the use of chemotherapy for the management of non-small cell lung cancer (NSCLC). Crit. Rev. Oncol. Hematol., 81, 49-57.

Kubota, K., Sakai, H., Katakami, N., Nishio, M., Inoue, A., Okamoto, H., Isobe, H., Kunitoh, H., Takiguchi, Y., Kobayashi, K., Nakamura, Y., Ohmatsu, H., Sugawara, S., Minato, K., Fukuda, M., et al. (2015) A randomized phase III trial of oral S-1 plus cisplatin versus docetaxel plus cisplatin in Japanese patients with advanced non-small-cell lung cancer: TCOG0701 CATS trial. Ann. Oncol., 26, 1401-1408.

Liang, H., Zhang, H., He, W. \& Zhang, Q. (2012) Outcomes of comparing S-1 plus cisplatin with Gemcitabine plus cisplatin for non-small-cell lung cancer. Chinese Journal of Geriatric Care, 10, 101-103.

Liu, B. \& Chen, G. (2013) Clinical observation in the first-line treatment of advanced NSCLC with gimeracil and oteracil porassium plus cisplatin or docetaxel plus cisplatin. Chin. J. Clin. Oncol. Rehabil., 20, 734-736.

Nishino, K., Imamura, F., Kumagai, T., Katakami, N., Hata, A., Okuda, C., Urata, Y., Hattori, Y., Tachihara, M., Yokota, S., Nishimura, T., Kaneda, T., Satouchi, M., Morita, S. \& Negoro, S. (2015) A randomized phase II study of bevacizumab in combination with docetaxel or S-1 in patients with non-squamous non-small-cell lung cancer previously treated with platinum based chemotherapy (HANSHIN Oncology Group 0110). Lung Cancer, 89, 146-153.

Nogami, N., Takigawa, N., Hotta, K., Segawa, Y., Kato, Y., Kozuki, T., Oze, I., Kishino, D., Aoe, K., Ueoka, H., Kuyama, S., Harita, S., Okada, T., Hosokawa, S., Inoue, K., et al. (2015) A phase II study of cisplatin plus S-1 with concurrent thoracic radiotherapy for locally advanced non-small-cell lung cancer: the Okayama Lung Cancer Study Group Trial 0501. Lung Cancer, 87, 141-147.

Okamoto, I. \& Fukuoka, M. (2009) S-1: a new oral fluoropyrimidine in the treatment of patients with advanced non-small-cell lung cancer. Clin. Lung Cancer, 10, 290-294.

Okamoto, I., Yoshioka, H., Morita, S., Ando, M., Takeda, K., Seto, T., Yamamoto, N., Saka, H., Asami, K., Hirashima, T., Kudoh, S., Satouchi, M., Ikeda, N., Iwamoto, Y., Sawa, T., et al. (2010) Phase III trial comparing oral S-1 plus carboplatin with paclitaxel plus carboplatin in chemotherapy-naive patients with advanced non-small-cell lung cancer: results of a west Japan oncology group study. J. Clin. Oncol., 28, 52405246.

Schiller, J.H., Harrington, D., Belani, C.P., Langer, C., Sandler, A., Krook, J., Zhu, J. \& Johnson, D.H. (2002) Comparison of four chemotherapy regimens for advanced non-small-cell lung cancer. N. Engl. J. Med., 346, 92-98.

Segawa, Y., Kiura, K., Hotta, K., Takigawa, N., Tabata, M., Matsuo, K., Yoshioka, H., Hayashi, H., Kawai, H., Aoe, K., Maeda, T., Ueoka, H. \& Tanimoto, M. (2010a) A randomized phase II study of a combination of docetaxel and S-1 versus docetaxel monotherapy in patients with non-small cell lung cancer previously treated with platinum-based chemotherapy: results of Okayama Lung Cancer Study Group (OLCSG) Trial 0503. J. Thorac. Oncol., 5, 1430-1434.

Segawa, Y., Kiura, K., Takigawa, N., Kamei, H., Harita, S., Hiraki, S., Watanabe, Y., Sugimoto, K., Shibayama, T., Yonei, T., Ueoka, H., Takemoto, M., Kanazawa, S., Takata, I., Nogami, N., et al. (2010b) Phase III trial comparing docetaxel and cisplatin combination chemotherapy with mitomycin, vindesine, and cisplatin combination chemotherapy with concurrent thoracic radiotherapy in locally advanced non-small-cell lung cancer: OLCSG 0007. J. Clin. Oncol., 28, 3299-3306.

Senan, S., Brade, A.M., Wang, L., Vansteenkiste, J.F., Dakhil, S.R., Biesma, B., Aguillo, M.M., Aerts, J., Govindan, R., RubioViqueira, B., Lewanski, C.R., Gandara, D.R., Choy, H., Mok,
T., Hossain, A., et al. (2015) Final overall survival (OS) results of the phase III PROCLAIM trial: Pemetrexed (Pem), cisplatin (Cis) or etoposide (Eto), Cis plus thoracic radiation therapy (TRT) followed by consolidation cytotoxic chemotherapy (CTX) in locally advanced non-squamous non-small cell lung cancer (nsNSCLC). J. Clin. Oncol., 33, suppl; abstr 7506.

Seto, T., Sasaki, T., Yamanaka, T., Kunitake, N., Shimizu, J., Kodaira, T., Nishio, M., Kozuka, T., Takahashi, T., Harada, H., Yoshimura, N., Tsutsumi, S., Kitajima, H., Kataoka, M., Nakagawa, K., et al. (2015) A randomized phase II study of TS-1 plus cisplatin versus vinorelbine plus cisplatin with concurrent thoracic radiotherapy for locally advanced nonsmall cell lung cancer (LA-NSCLC): WJOG 5008L. J. Clin. Oncol., 33, suppl; abstr 7512 .

Shirasaka, T. (2009) Development history and concept of an oral anticancer agent S-1 (TS-1): its clinical usefulness and future vistas. Jpn. J. Clin. Oncol., 39, 2-15.

Shirasaka, T., Nakano, K., Takechi, T., Satake, H., Uchida, J., Fujioka, A., Saito, H., Okabe, H., Oyama, K., Takeda, S., Unemi, N. \& Fukushima, M. (1996) Antitumor activity of 1 $\mathrm{M}$ tegafur-0.4 M 5-chloro-2,4-dihydroxypyridine-1 M potassium oxonate (S-1) against human colon carcinoma orthotopically implanted into nude rats. Cancer Res., 56, 2602-2606.

Shirasaka, T., Shimamoto, Y. \& Fukushima, M. (1993) Inhibition by oxonic acid of gastrointestinal toxicity of 5-fluorouracil without loss of its antitumor activity in rats. Cancer Res., 53, 4004-4009.

Shukuya, T., Takahashi, T., Harada, H., Akamatsu, H., Sakaguchi, C., Imai, H., Ono, A., Nakamura, Y., Tsuya, A., Kenmotsu, H., Naito, T., Murakami, H., Endo, M., Takahashi, K. \& Yamamoto, N. (2012) Comparison of vinorelbine plus cisplatin and S-1 plus cisplatin in concurrent chemoradiotherapeutic regimens for unresectable stage III non-small cell lung cancer. Anticancer Res., 32, 675-680.

Siegel, R., Ma, J., Zou, Z. \& Jemal, A. (2014) Cancer statistics, 2014. CA Cancer J. Clin., 64, 9-29.

Sugawara, S., Maemondo, M., Tachihara, M., Inoue, A., Ishimoto, O., Sakakibara, T., Usui, K., Watanabe, H., Matsubara, N., Watanabe, K., Kanazawa, K., Ishida, T., Saijo, Y. \& Nukiwa, T. (2013) Randomized phase II trial of uracil/tegafur and cisplatin versus vinorelbine and cisplatin with concurrent thoracic radiotherapy for locally advanced unresectable stage III nonsmall-cell lung cancer: NJLCG 0601. Lung Cancer, 81, 91-96.

Sun, C., Wu, G., Yan, W., Sun, Q. \& Liu, B. (2015) Clinical observation of tegafur/gimeracil/oteracil potassium plus cisplatin versus gemcitabine plus cisplatin as the first-line therapies advanced NSCLC with wild-type EGFR. Chin. Hosp. Pharm. $J ., 35,2129-2132$.

Takechi, T., Nakano, K., Uchida, J., Mita, A., Toko, K., Takeda, S., Unemi, N. \& Shirasaka, T. (1997) Antitumor activity and low intestinal toxicity of S-1, a new formulation of oral tegafur, in experimental tumor models in rats. Cancer Chemother. Pharmacol., 39, 205-211.

Tsai, C.M., Hsiao, S.H., Frey, C.M., Chang, K.T., Perng, R.P., Gazdar, A.F. \& Kramer, B.S. (1993) Combination cytotoxic effects of cis-diamminedichloroplatinum(II) and 5-fluorouracil with and without leucovorin against human non-small cell lung cancer cell lines. Cancer Res., 53, 1079-1084.

Yamamoto, N., Nakagawa, K., Nishimura, Y., Tsujino, K., Satouchi, M., Kudo, S., Hida, T., Kawahara, M., Takeda, K., Katakami, N., Sawa, T., Yokota, S., Seto, T., Imamura, F., Saka, H., et al. (2010a) Phase III study comparing secondand third-generation regimens with concurrent thoracic radiotherapy in patients with unresectable stage III non-small-cell lung cancer: West Japan Thoracic Oncology Group WJTOG0105. J. Clin. Oncol., 28, 3739-3745.

Yamamoto, N., Yamanaka, T., Ichinose, Y., Kubota, K., Sakai, H., 
Gemma, A., Saijo, N., Fukuoka, M. \& Niitani, H. (2010b) Pooled analysis of S-1 trials in non-small cell lung cancer according to histological type. Anticancer Res., 30, 29852990.

Yan, F. \& Li, X. (2013) Evaluation of efficacy and safety of Tegafur chemotherapy in the treatment of middle-advanced lung cancer. Chin. J. Clin. Oncol. Rehabil., 20, 359-361.

Yanagihara, K., Yoshimura, K., Niimi, M., Yasuda, H., Sasaki, T., Nishimura, T., Ishiguro, H., Matsumoto, S., Kitano, T., Kanai, M., Misawa, A., Tada, H., Teramukai, S., Mio, T. \& Fukushima, M. (2010) Phase II study of S-1 and docetaxel for previously treated patients with locally advanced or metastatic non-small cell lung cancer. Cancer Chemother. Pharmacol., 66, 913-918.
Yao, L., Xu, S., Xu, J., Yang, C., Wang, J. \& Sun, D. (2015) S-1 plus cisplatin with concurrent radiotherapy versus cisplatin alone with concurrent radiotherapy for stage III non-small cell lung cancer: a pilot randomized controlled trial. Radiat. Oncol., 10, 10.

Yoshioka, H., Okamoto, I., Morita, S., Ando, M., Takeda, K., Seto, T., Yamamoto, N., Saka, H., Atagi, S., Hirashima, T., Kudoh, S., Satouchi, M., Ikeda, N., Iwamoto, Y., Sawa, T., et al. (2013) Efficacy and safety analysis according to histology for S-1 in combination with carboplatin as first-line chemotherapy in patients with advanced non-small-cell lung cancer: updated results of the West Japan Oncology Group LETS study. Ann. Oncol., 24, 1326-1331. 